\title{
Molecular cloning and characterization of an alkalophilic Bacillus sp. C125 gene homologous to Bacillus subtilis $\sec Y$
}

\author{
SHIN-Kwon Kang, ${ }^{1}$ Toshiaki KUdO ${ }^{1,2 *}$ and KOKI HoRIKOSHI ${ }^{1}$ \\ Laboratory of Microbiology ${ }^{1}$ and Biodesign Research Group ${ }^{2}$, Riken Institute and JRDC, Wako, Saitama 351-01, Japan
}

(Received 4 February 1992; revised 25 March 1992; accepted 2 April 1992)

\begin{abstract}
A $1.8 \mathrm{~kb}$ HindIII DNA fragment containing the $\sec Y$ gene of alkalophilic Bacillus sp. $\mathrm{C125}$ has been cloned into plasmid pUC119 using the $B$. subtilis sec $Y$ gene as a probe. The complete nucleotide sequence of the cloned DNA indicated that it contained one complete ORF and parts of two other ORFs. The similarity of these ORFs to the sequences of the $B$. subtilis proteins indicated that they were the genes for ribosomal protein L15-SecY-adenylate kinase, in that order. The gene product of the alkalophilic Bacillus sp. C125 sec $Y$ homologue was composed of 431 amino acids and its $M_{\mathrm{r}}$ value has been calculated to be $\mathbf{4 7 1 0 0}$. The distribution of hydrophobic amino acids in the gene product suggested that the protein was a membrane integrated protein with ten transmembrane segments. The total amino acid sequence of alkalophilic Bacillus sp. C125 secY homologue showed $69.7 \%$ homology with that of $B$. subtilis sec $Y$. Regions of remarkably high homology ( $78 \%$ identity) were present in transmembrane regions, and cytoplasmic domains ( $73 \%$ identity) with less homologous regions present in extracellular domains ( $43 \%$ identity).
\end{abstract}

\section{Introduction}

Genetic studies suggest that a secretion machinery exists for the export of protein to the cell envelope (Michaelis \& Beckwith, 1982). The prl series of genes, prlA (secY) (Ito et al., 1983), prlB, prlC and prlD (Emr et al., 1981; Bankatis \& Bassford, 1985) identified by their ability to suppress mutations of an export-defective signal peptide, are believed to be involved in the secretion machinery of Escherichia coli. One of these genes, $\sec Y(\mathrm{prlA})$, encodes an integral membrane protein of 10 transmembrane segments (Akiyama \& Ito, 1987) which is essential for protein export from the cytosol to the periplasm or outer membrane.

Bacillus sp. strains have a remarkable ability to secrete many proteins, such as amylases, cellulases or proteases, into the culture medium. Recently several groups isolated and analysed the $\sec Y$ gene from $B$. subtilis (Yoshikawa \& Doi, 1990; Nakamura et al., 1990). However, the protein export pathway or other protein components related to the protein secretion process in Bacillus remain unclear.

Our group has a specific interest in alkalophilic

* Author for correspondence. Tel. 484621111 ; fax 484665209.

The nucleotide sequence data reported in this paper have been submitted to GenBank and have been assigned the accession number D10360.

Abbreviation: Adk, adenylate kinase. bacteria (Horikoshi, 1991) and have recently selected alkalophilic Bacillus sp. C125 as a model alkalophile for molecular biological study (Kudo et al., 1990). In alkalophiles a cell-membrane-maintained $\mathrm{pH}$ difference between the internal ( $\mathrm{pH} 8-8 \cdot 6)$ and the external ( $\mathrm{pH} 10$ 11) environments exists. A membrane protein is likely to show special adaptations to alkaline conditions. In order to clarify the protein secretion system in alkalophilic Bacillus and to study the $\sec Y$ protein as a model membrane protein, the $\sec Y$ gene of alkalophilic Bacillus sp. $\mathrm{C} 125$ was cloned using the $B$. subtilis $\sec Y$ gene as a probe, and the cloned gene was characterized.

\section{Methods}

Bacterial strains and plasmid. Alkalophilic Bacillus sp. C125 (Trp $\mathrm{Ura}^{-} \mathrm{Cm}^{\mathrm{s}}$ ) (Kudo et al., 1990) was used as the DNA source for Southern hybridization analysis and cloning of the $\sec Y$ gene. $E$. coli JM109 [recAl endAl gyrA96 thi-l hsdRI7 supE44 relAl $\lambda^{-} \Delta($ lacpro $A B)$ ( $\mathrm{F}^{\prime}$ pro $A B$ lacI ${ }^{q} Z \Delta M 15$ traD36)] was used as the host (Nakamura et al., 1990). Plasmid pSY912 containing the $B$. subtilis $\sec Y$ gene was kindly provided by $\mathrm{Dr} \mathrm{H}$. Yoshikawa (Tokyo University, Tokyo, Japan) and used as a probe (Yoshikawa et al., 1990).

Media and maintenance of strains. E. coli strain JM109 was grown and maintained on LB medium (Maniatis et al., 1982). When necessary, ampicillin was added to the medium $\left(100 \mu \mathrm{g} \mathrm{ml}^{-1}\right)$. Alkalophilic Bacillus sp. C125 was grown and maintained on Horikoshi II medium (Kudo et al., 1990). 
General DNA techniques. DNA manipulations and transformation of E. coli were accomplished by the methods outlined by Maniatis et al. (1982).

Southern hybridization. Alkalophilic Bacillus sp. C125 chromosomal DNA was digested with restriction endonucleases, electrophoresed on a $1 \%(\mathrm{w} / \mathrm{v})$ agarose gel and then blotted on to a nylon membrane (Amersham) by the method of Southern (Southern, 1975). The membrane was prehybridized and hybridized in a $20 \%(\mathrm{v} / \mathrm{v})$ formamide hybridization solution at $42^{\circ} \mathrm{C}$. Subsequent washing and DNA detection were carried out according to the protocol provided with the digoxigenin DNA labelling and detection kit (Boehringer Mannheim).

Sequence analysis. Nucleotide sequencing was carried out by the method of Sanger et al. (1977) on an Applied Biosystems DNA sequencer (373A) using single-stranded DNA prepared by the method of Vieira \& Messing (1987) and an Applied Biosystems sequencing kit. Exonuclease III deletions were carried out by the method of Henikoff (1984). The DNA sequences were analysed using Macmolly Software.

\section{Results and Discussion}

\section{Cloning of $\sec Y D N A$}

To verify the existence of the $\sec Y$ gene in alkalophilic Bacillus sp. C125 chromosomal DNA, the DNA was digested with HindIII or EcoRI and then analysed by Southern hybridization using the $B$. subtilis $\sec Y$ gene as a probe (Fig. 1). A $1.8 \mathrm{~kb}$ HindIII fragment and two $E c o$ RI fragments $(5$ and $0.5 \mathrm{~kb})$ were detected. The $1.8 \mathrm{~kb}$ HindIII fragment was chosen for cloning since it gave a strong signal and the size was such that it was likely to contain the complete $\sec Y$ gene. Fragments of HindIII-digested Bacillus sp. C125 DNA of $1.8 \mathrm{~kb}$ were purified from a $1 \%(\mathrm{w} / \mathrm{v})$ agarose gel by electroelution, cloned into the HindIII site of pUC119 and transformed into E. coli. Two-thousand $\mathrm{Amp}^{\mathrm{r}}$ transformants were subjected to colony hybridization analysis and two positive colonies identified. Southern analysis of purified plasmid DNA from these two positive colonies showed positive bands. Restriction mapping of the two plasmids revealed that they contained the same $1.8 \mathrm{~kb}$ fragment in the same orientation. The plasmid was designated as pASY3. The physical map of the $1.8 \mathrm{~kb}$ HindIII fragment contained in pASY3 is presented in Fig. 2.

\section{DNA sequence analysis of the $\sec Y$ gene of alkalophilic}

Bacillus sp. CI25

The nucleotide sequence of the entire $1.8 \mathrm{~kb}$ fragment contained in pASY3 was determined. The nucleotide and deduced amino acid sequences are presented in Fig. 3. Three ORFs, all in the same orientation, were identified. The first ORF lacking the $\mathrm{N}$-terminal region consisted of 66 amino acids. This ORF shared $79.1 \%$ amino acid identity $(51 / 66)$ with the ribosomal protein

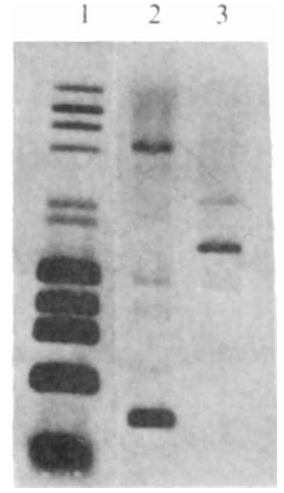

Fig. 1. Southern hybridization analysis of alkalophilıc Bacillus sp. C125 chromosomal DNA. Lanes: 1, Size marker (HindIII-digested $\lambda$ DNA and HaelII-digested $\phi$ X174 DNA mixture); 2, EcoRI-digested C125 DNA; 3, HindIII-digested C125 DNA. The plasmid pSY912 containing the $B$. subtilis $\sec Y$ gene was used as a probe.

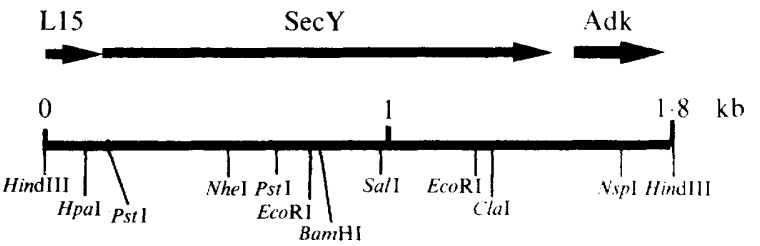

Fig. 2. Physical map and alignment of the three ORFs in the cloned $1.8 \mathrm{~kb}$ HindIII fragment from alkalophilic Bacillus sp. C125 chromosomal DNA.

L15 of B. subtilis (Yoshikawa \& Doi, 1990; Nakamura et al., 1990). The second ORF, beginning with an ATG codon at position 202, consisted of 431 amino acids and showed $69.7 \%$ amino acid identity with the $B$. subtilis $\sec Y$ gene product (Yoshikawa \& Doi, 1990; Nakamura et al., 1990). The third ORF, beginning with a TTG codon at position 1570, consisted of 107 amino acids and was terminated by the HindIII site. This ORF had $78.5 \%$ amino acid identity with the $B$. subtilis adk gene product (Yoshikawa \& Doi, 1990; Nakamura et al., 1990). Typical sequences for ribosomal binding, upstream of the 2nd and 3rd ORFs were observed. These results indicated that the gene order around $\sec Y$, given by the deduced gene product sequences was L15-SecY-adenylate kinase (Adk) and identical to that observed in $B$. subtilis.

The predicted amino acid sequence of the $\sec Y$ gene product of alkalophilic Bacillus sp. C125 was compared with that of the B. subtilis sec $Y$ gene product (Fig. 4) (Yoshikawa \& Doi, 1990). The number of amino acid residues of both gene products was the same (431 amino acids) and alkalophilic Bacillus sp. C125 SecY shared $69.7 \%$ amino acid identity with $B$. subtilis SecY. The hydrophobic profiles in the amino acid sequences were analysed by the procedure of Kyte \& Doolittle (1982). 


\section{L15}

Lys Leu Amn Arg Phe Glu Asp Gly Thr Glu Val Ser Pro Glu Leu Leu Leu Glu AAG CIT AAT CGT TIT GAA GAT GGA ACA GAG GTT TCA CCA GAA CTT ITG CIT GAA HindIII

Thr Gly Val Val Ser Asn Ala Lys Asp Gly Ile Lys Ile Leu Gly Asn Gly Lys Leu Glu ACA GGT GTT GIT AGC AAC GCA AAG GAC GGC ATT AAG ATC CTC GGT AAT GGA AAG CTA GAG

Lyв Lyв Leu Thr Val Lys Ala Asn Lyв Phe Ser Ala ser Ala Val Glu Ala Ile Glu Ala AAG AAG TIA ACA GTG AAA GCC AAC AAA TTC TCT GCT TCT GCA GTG GAA GCT ATT GAA GCT $\mathrm{HpaI}$

SecY Pst $\mathrm{I}$

Ala Gly Gly Lys Thr Glu Val Ile TFR Met Phe Arg Thr Ile Ser Asn Ile Phe Arg Val GCC GGC GGG AAA ACT GAG GTG ATC TAA ATG TTC CGA ACG ATC TCC AAC ATT TTT CGA GTG SD

Gly Aap Leu Arg Arg Lys Val Ile Phe Thr Leu Leu Met Leu Ile Val Phe Arg Ile Gly GGT GAT TTG CGC CGT AAG GTC ATT TTC ACC CTG CTC ATG CTC ATC GTT TTT CGG ATC GGA

Ser Phe Ile Pro Val Pro Gly Thr Amn Arg Glu Val Leu Asp Phe Val Aop Gln Ala Amn AGT TTT ATC CCC GTT CCA GGT ACA AAC CGA GAA GTG CTA GAT TTT GTC GAT CAG GCA AAT

Ala Phe Gly Phe Leu Asn Thr Phe Gly Gly Gly Ala Leu Gly Asn Phe Ser Ile Phe Ala GCA TTC GGT TTT TTA AAT ACG TIT GGA GGA GGG GCA CTI GGG AAT TTC TCC ATC TIT GCG

Met Gly Ile Met Pro Tyr Ile Thr Ala Ser Ile Val Met Gln Leu Leu Gln Met Arp Val ATG GGG ATC ATG CCA TAC ATT ACA GCA TCC ATT GTC ATG CAA TTA TTG CAG ATG GAT GTC

Val Pro Lya Phe Ala Glu Trp Ala Lys Glu Gly Glu Ala Gly Arg Arg Lys Leu Ala Gln GTT CCG AAA TIT GCT GAG TGG GCG AAA GAG GGC GAA GCA GGG CGP CGT AAG CTA GCT CAA Nhel

Phe Thr Arg Tyr Gly Thr Ile val Val Leu Gly Phe Ile Gln Ala Leu Gly Met Ser Val TTT ACC CGC TAT GGA ACG ATT GTT GTT ITA GGG TTT ATT CAG GCA CTC GGG ATG TCG GTT

Gly Phe Asn Asn Phe Phe Pro Gly Leu Ile Pro Amn Pro Ser Val Ser Val Tyr Leu Phe GGT TTT AAC AAC TTC TTC CCA GGA TTA ATT CCT AAT CCA AGC GTG TCG GTG TAT CTC TTT

Ile Ala Leu Val Leu Thr Ala Gly Thr Ala Phe Leu Met Trp Leu Gly Glu Gln Ile Thr ATC GCA CTT GTC CTT ACT GCA GGA ACG GCT TTC TTA ATG TGG CTC GGG GAG CAG ATT ACA Pst $\mathrm{I}$

Ala Lye Gly Val Gly Aøn Gly Ile Ser Ile Ile Ile Phe Ala Gly Ile Ala Ala Gly Ile GCT AAG GGA GTC GGA AAC GGA ATC TCC ATT ATC ATC TTT GCA GGG ATT GCT GCT GGA ATT

EcoRI

Pro Asn Gly Leu Asn Leu Ile Tyr Ser Thr Arg Ile Gln Asp Ala Gly Glu GIn Leu Phe CCA AAT GGG TTA AAT CTC ATP TAC TCA ACA CGG ATC CAA GAC GCA GGG GAG CAA TTG TTC BamHI

Leu Asn Ile Val Val Ile Leu Leu Leu Ala Leu Ala Ile Leu Ala Ile Ile Val Gly Val TTG AAC ATT GTG GTG ATC TTG TTG CIT GCT CTT GCG ATT CTP GCC ATC ATT GTG GGC GTT

Ile Phe Val Gln Gln Ala Leu Arg Lye Ile Pro Val Gln Tyr Ala Lys Arg Leu Val Gly ATT TTC GTC CAA CAA GCG TTG CGT AAA ATC CCT GTT CAG TAT GCC AAG CGT CTA GTA GGG

Arg Asn Pro Val Gly Gly Gln ser Thr His Leu Pro Leu Lye Val Asn Ala Ala Gly Val AGA AAC CCT GTT GGA GGT CAG TOG ACC CAT CTT CCG TTA AAA GTG AAT GCC GCA GGC GTT SalI

Ile Pro Val Ile Phe Ala Leu Ser Leu Leu Ile Phe Pro Pro Thr Val Ala Gly Leu Phe ATT CCG GTC ATT TTT GCG TTA TCG TTG CTC ATT TTT CCA CCA ACG GTT GCT GGG CTG TIT

Gly Ser Aep His Pro Val Ala Ala Trp Val Ile Glu Thr Phe Aøp Tyr Thr His Leu Ile GGC AGT GAT CAT CCG GTC GCT GCA TGG GTG ATT GAG ACA TTT GAC TAT ACC CAC TTG ATT

Gly Met Ala Val Tyr Ala Leu Arg Ile Ile Gly Phe Thr Tyr Phe Tyr Ala Phe Ile Gln GGG ATG GCG GTA TAT GCC TTG CGC ATC ATC GGA TTT ACG TAT TTC TAT GCG TTT ATC CAA

Val Asn Pro Glu Arg Met Ala Glu Asn Leu Lys Lys Gin Gly Gly Tyr Ile Pro Gly Ile GTC AAC CCA GAG CGA ATG GCG GAG AAC TTG AAA AAA CAG GGT GGC TAT ATT CCT GGA ATT

EcoRI

Arg Pro Gly Lye Ala Thr Gln Thr Tyr Ile Thr Pro Ile Leu Tyr Arg Leu Thr Phe Val CGT CCA GGG AAA GCA ACG CAG ACG TAC ATC ACG CCT ATC TTG TAT CGA ITA ACG TTT GTC

Fig. 3. 
Gly Ser Leu Phe Leu Ala Val Val Ala Ile Leu Pro Val Phe Phe Ile Lys Phe Ala Asp GGA TCA CIT TTC CTC GCA GTG GTG GCG ATC TTG COG GTA TTC TTT ATT AAG TTT GCC GAC

Leu Pro Gln Ala Ile Gln Ile Gly Gly Thr Gly Leu Leu Ile Val Val Gly Val Ala Leu TTG CCA CAG GCG ATT CAA ATT GGT GGT ACG GGC TTG CTC ATC GTC GTC GGG GTT GCC CTI

Aвp Thr Met Lys Gln Ile Glu Ala Gln Leu Ile Lys Arg Ser Tyr Lys Gly Phe Ile Lys GAT ACG ATG AAG CAA ATT GAA GCA CAG TTG ATC AAA CGT TCT TAT AAA GGG TPT ATT AAG

TER Adk

Met Ann Leu Asn Leu Met Gly Leu Pro Gly Ala Gly Lys Gly Thr GTG GAG GGG ATA GAC TTG AAT CTG AAC CIT ATG GGA CTT CCT GGT GCT GGT AAA GGT ACA $\mathrm{SD}$

Gin Ala Glu Lys Ile Ile Glu Lys Tyr Gly Ile Pro His Ile Ser Thr Gly Asp Met Phe CAG GCA GAA AAG ATC ATT GAG AAG TAC GGC ATC CCA CAC ATT TCA ACA GGT GAC ATG TTT

$$
\text { Nspl }
$$

Arg Ala Ala Met Lys Asn Glu Thr Glu Leu Gly Leu Lys Ala Lys Ser Tyr Met Aap Ala CGT GCT GCG ATG AAG AAC GAG ACC GAG CTT GGA TTA AAA GCA AAA TCG TAC ATG GAT GCA

Gly Glu Leu Val Pro Asp Glu Val Thr Ile Gly Ile Val Arg Aep Arg Leu Ser Gln Aвp GGG GAA CTG GTT CCT GAT GAA GTA ACG ATT GGT ATC GTT CGG GAT CGT CTC AGT CAA GAC

Asp Cys Gln Asn Gly Phe Leu Leu Asp Gly Phe Pro Arg Thr Val Ala Gln Ala Glu Ala GAT TGC CAA AAT GGC TTT TTG CIT GAC GGG TTP CCA CGG ACT GTC GCT CAA GCA GAA GCG

Leu Glu Aвp Ile Leu Ala Ser Leu Aвp Lyв Lyв Leu

TTA GAA GAT ATT TTG GCG TCA CIT GAT AAA AAG CIT

HindIII

Fig. 3. Nucleotide and deduced amino acid sequences of the $1.8 \mathrm{~kb}$ HindIII fragment. Nucleotides are numbered from the 5 -end. The possible ribosome binding sites (SD) preceding each of the ORFs are underlined.
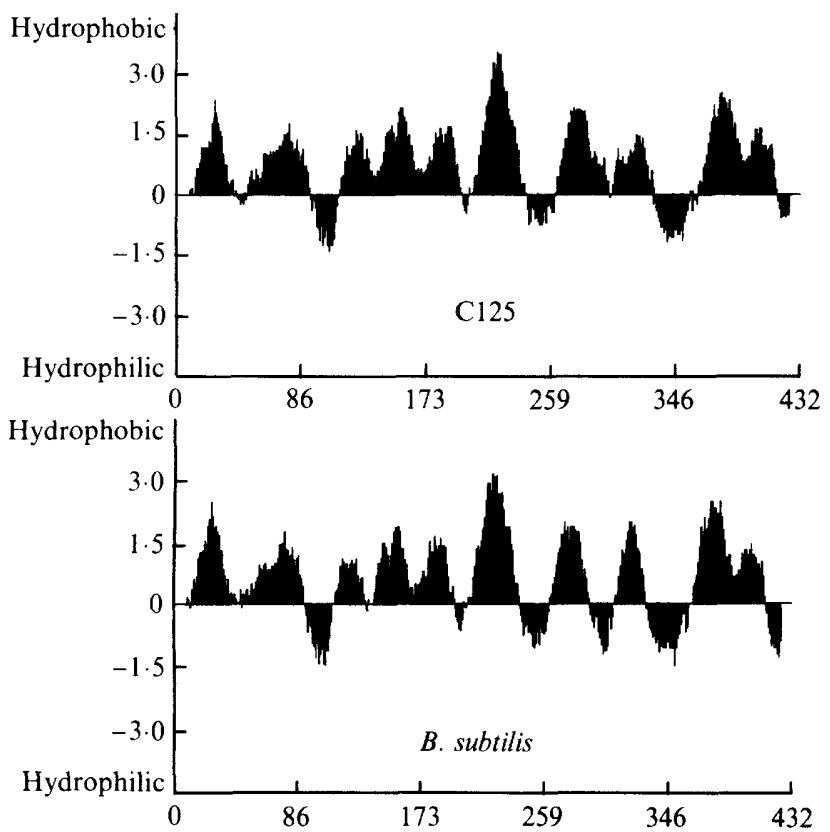

Fig. 4. Hydrophobic profiles for the SecY protein of alkalophilic Bacillus $\mathrm{sp}$. $\mathrm{C} 125$ and $B$. subtilis. Hydrophobic profiles were calculated by the procedure of Kyte \& Doolittle (1982).
The. hydrophobic profile of alkalophilic Bacillus sp. $\mathrm{C} 125 \mathrm{SecY}$ was similar to that of B. subtilis SecY (Fig. 4). It appeared that alkalophilic Bacillus sp. C125 SecY contains the same 10 hydrophobic regions as those of $B$. subtilis SecY. Highly homologous regions between $B$. subtilis and alkalophilic Bacillus sp. C125 SecY were found in the membrane domains (about $78 \%$ identity) and the cytoplasmic domains $(73 \%$ identity). Less homologous regions $(43 \%$ identity) were present in extracellular domains (Fig. 5). Two possibilities are considered. First, more variation is tolerated in the extracellular region and the greater divergence is due to genetic drift because $E$. coli and $B$. subtilis $\operatorname{Sec} Y$ extracellular regions were not so conserved compared with those of membrane or intracellular domains. Second, higher sequence variation seen with the extracellular domains of the protein may be a response to the alkaline environment. Due to the high level of variation in the extracellular regions it is difficult to pinpoint and investigate possible changes in the alkalophilic Bacillus sp. C125 SecY protein that may contribute to its adaptation to alkaline conditions. A comparison of the amino acid composition of the extracellular domains, 
1

1. MFRTISNIFRVGDLRR VIFTLLMLIVFRIGSFIPVPGTNREVLDFVDQANAFGFLNTFG

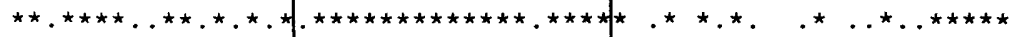

I" MFKTISNFMRVSDIRNKII IFTLIMLIVFRIGAFIPUPYVNAEALQAQSQMGVFDLLNTFG

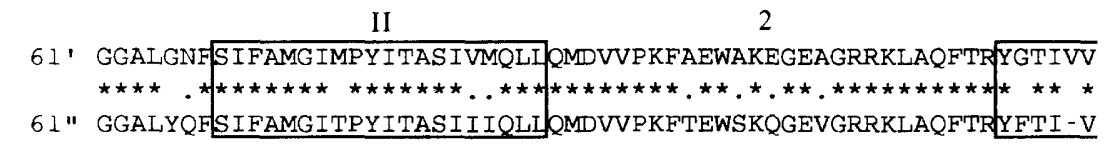

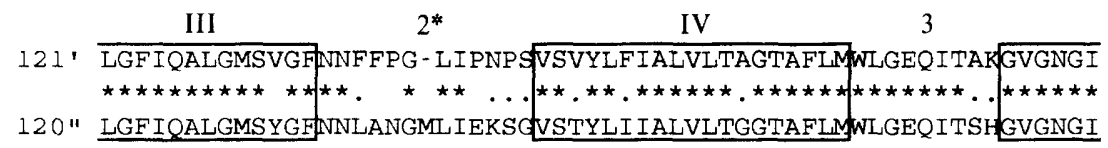

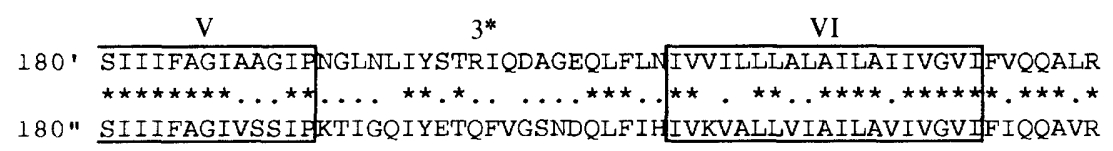

4 VII 4 *

240. KIPVQYAKRLVGRNPV-GGQSTHLPLKVNAAGVIPVIFALSLLIFPPTVAGLFGSDHPVA

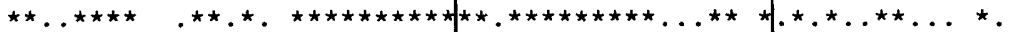

$240 "$ KIAIQYAKG -TGRSPAGGGQSTHLPLKUNPAGVIPVIFAVAFLITPRTIASFFGTND-VT

VIII 5

299 AWVIETFDYTH LIGMAVYALRI IGFTYFYAFIQVNPERMAENLKKQGGYIPGIRPGKATQ

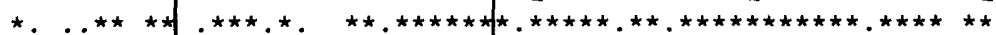

$298 "$ KWIQNNFDNTH PVGMA IYVALI IAFTYFYA FVQVNPEQMADNLKKQGGY I PGVRPGKMTQ

IX $5^{*} \quad \mathrm{X}$

359 TYITPILYRI TFVGSLFLAVVAILPVFF TKFADLP AIQIGGTGLIIVVGVALDTMKQIE

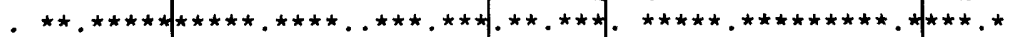

358" DRITSILYRITFVGS IFLAVISILPIFFIQFAGLP SSAQIGGTSLLIVVGVALETMKQLE

6

419, AQLIKRSYKGFIK $. \star \star . * \star . \star . * \star . *$

C125 (431)

$418 "$ SQLVKRNYRGFMKN

B. subtilis (431)

Table 1. Comparison of amino acid composition of the extracellular region of alkalophilic Bacillus C-125 and Bacillus subtilis SecY proteins

\begin{tabular}{ccccccc}
\hline \hline & \multicolumn{2}{c}{ Extracellular region } & & \multicolumn{2}{c}{ Extracellular region } \\
\cline { 2 - 3 } \cline { 5 - 6 } Amino acid & C125 & B. subtilis & Amino acid & C125 & B. subtilis \\
\hline Ile & 4 & 6 & Thr & 6 & 7 \\
Leu & 10 & 8 & Gln & 4 & 10 \\
Gly & 11 & 10 & Asn & 4 & 6 \\
Ala & 8 & 7 & Ser & 4 & 5 \\
Val & 5 & 4 & Arg & 2 & 1 \\
Phe & 11 & 9 & Lys & 1 & 3 \\
Pro & 7 & 2 & Thr & 2 & 3 \\
Met & 0 & 1 & Glu & 3 & 3 \\
Trp & 1 & 1 & Asp & 6 & 4 \\
His & 2 & 2 & & & \\
\hline \hline
\end{tabular}

Fig. 5. Alignment of identical residues $(\star)$ between the predicted amino acid sequences for alkalophilic Bacillus sp. C125 sec $Y$ and B. subtilis $\sec Y$ gene products. The membrane-spanning regions (I-X) were deduced according to the results of hydrophobic profiles calculated by the procedure of Kyte \& Doolittle (1982). Extracellular regions $\left(1^{*}-5^{*}\right)$ and intracellular regions (1-6) are also indicated. A dot indicates similar amino acids. however, indicated that in the alkalophilic Bacillus sp. $\mathrm{C} 125$ protein, the number of proline residues increased mainly in extracellular domains $2^{*}$ and $4^{*}$ and the number of glutamine residues decreased mainly in extracellular domain $3^{*}$, compared with those of the $B$. subtilis protein (Table 1). The role of the extracellular region of the SecY protein is not clear but it appears that these amino acid residues may play some role in alkaline conditioning of the protein from alkalophilic Bacillus sp. C125. 
We are grateful to Dr H. Yoshikawa for providing plasmid pSY912 containing the entire region of the Bacillus subtilis sec $Y$ gene. We also thank Dr Yamane, University of Tsukuba, Japan, for the useful discussions pertaining to Southern Hybridization Techniques and $\mathrm{Dr}$ Kate Sutherland for reading the manuscript and for many helpful discussions. This work was partially supported by a grant for the 'Biodesign Research Program' from Riken to T. Kudo.

\section{References}

AkiYama, Y. \& ITo, K. (1987). Topology analysis of the $\sec Y$ protein, an integral membrane protein involved in protein export in Escherichia coli. EMBO Journal 6, 3465-3470.

BanKatis, V. \& BASSFORD, P. (1985). Proper interaction between at least two components is required for efficient export of proteins to the Escherichia coli cell envelope. Journal of Bacteriology 161, 169178 .

Emr, S., Hanley-Way, S. \& Shilhavy, T. (1981). Suppressor mutations that restore export of a protein with a defective signal sequence. Cell 23, 79-88.

HENIKOFF, S. (1984). Undirectional digestion with exonuclease III creates targeted breakpoints for DNA sequencing. Gene 28, 351-359.

HoRIKOSHI, K. (1991). Microorganisms in the Alkaline Environment. Tokyo: Kodansha.
Ito, K., Wittexind, M., Nomura, M., Shiba, K., Yura, T., Miura, A. \& NaShimoto, H. (1983). A temperature-sensitive mutant of $E$. coli. exhibiting slow processing of exported proteins. Cell 32, 789-797.

Kudo, T., Hino, M., Kitada, M. \& HoRikoshi, K. (1990). DNA sequences required for the alkalophily of Bacillus sp. strain C125 are located close together on its chromosomal DNA. Journal of Bacteriology 172, 7282-7283.

K YTE, J. \& DoolitTle, R. F. (1982). A simple method for displaying the hydropathic character of a protein. Journal of Molecular Biology 157, 105-132.

Maniatis, T., Fritsch, E. F. \& Sambrook, J. (1982). Molecular Cloning: A Laboratory Manual. Cold Spring Harbor, NY: Cold Spring Harbor Laboratory.

MiChAELIS, S. \& BECKWITH, J. (1982). Mechanism of incorporation of cell envelope proteins in Escherichia coli. Annual Review of Microbiology 36, 435-465.

Nakamura, K., Nakamura, A., Takamatsu, H., Yoshikawa, H. \& YAMANE, K. (1990). Cloning and characterization of a Bacillus subtilis gene homologous to E. coli sec Y. Journal of Biochemistry 107, 603-607.

SANGer, F., Nicklen, S. \& Coulson, A. (1977). DNA sequencing with chain-terminating inhibitors. Proceedings of the National Academy of Sciences of the United States of America 74, 5463-5467.

SOUTHERN, E. M. (1975). Detection of specific sequences among DNA fragments separated by gel electrophoresis. Journal of Molecular Biology 98, 503-517.

VieIRA, J. \& MESSING, J. (1987). Production of single-stranded plasmid DNA. Methods in Enzymology 153, 3-11.

Yoshikawa, H. \& DoI, R. (1990). Sequence of the Bacillus subtilis spectinomycin resistance gene region. Nucleic Acids Research 18, 1647. 